\title{
Strand Orientation by Steric Matching: A Designed Antiparallel Coiled-Coil Trimer
}

\author{
Nathan A. Schnarr and Alan J. Kennan* \\ Department of Chemistry, Colorado State University Fort Collins, Colorado 80523
}

\section{Supporting Information:}

\section{General Procedures:}

Peptide Synthesis. Amino acids (including cyclohexylalanine) were obtained from NovaBiochem (San Diego). Peptides were prepared according to the in situ neutralization protocol developed by Kent. ${ }^{1}$ Each peptide was purified by reverse-phase HPLC (C-18 column, solvent $\mathrm{A}$ : $1 \% \mathrm{CH}_{3} \mathrm{CN}$ in $\mathrm{H}_{2} \mathrm{O}, 0.1 \%$ (v/v) $\mathrm{CF}_{3} \mathrm{CO}_{2} \mathrm{H}$; solvent $\mathrm{B}: 10 \% \mathrm{H}_{2} \mathrm{O}$ in $\mathrm{CH}_{3} \mathrm{CN}, 0.07 \%$ (v/v) $\left.\mathrm{CF}_{3} \mathrm{CO}_{2} \mathrm{H}\right)$, and the identity of purified samples was confirmed by electrospray mass spectrometry (Finnegan LCQ-Duo). All peptides are C-terminally amidated and N-terminally acetylated; each contains an acetamidobenzoate group on the sidechain nitrogen of a solventexposed lysine as a spectroscopic label.

Ni-NTA Affinity Tag Experiments. A $0.5 \mathrm{~mL}$ sample of a 50\% slurry of Ni-NTA agarose (Qiagen) in an Eppendorf tube was centrifuged for $30 \mathrm{~s}$, followed by removal of the superantant. Peptide solution was added, and the tube was repeatedly inverted for 5 minutes. The sample was centrifuged (30 s) and the supernatant (flow-through fraction) was removed. The procedure was then repeated with $1 \mathrm{~mL}$ of buffer (wash fraction) and $1 \mathrm{~mL}$ of buffer containing $250 \mathrm{mM}$ imidazole (elution fraction), except that the wash fraction was only agitated for 30 seconds. Solutions were analyzed by RP-HPLC. ${ }^{2}$

CD Spectroscopy. All experiments were performed on an Aviv model 202 circular dichroism spectrometer, equipped with a Microlab 500 series automated titration assembly. Sample concentrations were measured by UV absorbance of the acetamidobenzoate label at $270 \mathrm{~nm}$. Wavelength data are the average of three scans from 250 to $200 \mathrm{~nm}$ in $1 \mathrm{~nm}$ steps. Thermal denaturation experiments at $222 \mathrm{~nm}$ were run from $0^{\circ}$ to $90^{\circ} \mathrm{C}$ in two-degree steps, at a twodegrees/minute rate of increase with one-minute equilibration and data averaging at each temperature. $T_{m}$ values were obtained from minima of the first derivative of $\theta$ vs. 1/T plots. ${ }^{3}$ Guanidinium titrations were performed using the automated titration assembly. The signal at $222 \mathrm{~nm}$ was recorded for solutions of constant peptide concentration with guanidine hydrochloride concentrations varied from 0 to 3M. Data were collected for one minute at each step, with ten-minute equilibration times (solutions were stirred during equilibration but not data collection).

(1) Schnöelzer, M.; Alewood, P.; Jones, A.; Alewood, D.; Kent, S. B. H. Int. J. Pept. Protein Res. 1992, 40, 180-193.

(2) Method patterned after that in: Brown, M. B.; Sauer, R. T. Proc. Nat. Acad. Sci. U.S.A., 1999, 96, 1983-1988.

(3) Cantor, C. R.; Schimmel, P. R. Biophysical Chemistry of Macromolecules, Pt. 3: The Behavior of Biological Macromolecules; W. H. Freeman: New York, NY, 1980, p.1132. 
Disulfide Exhange Assay. Five derivatives were prepared by attaching a Gly-Gly-Cys sequence to the $\mathrm{N}$-terminus of $\mathrm{T}_{9} \mathrm{~K}\left(\mathrm{~T}_{9} \mathrm{~K}_{\mathrm{N}-\mathrm{Cys}}\right.$ ), and separately to the $\mathrm{N}$ - and C-termini of $\mathrm{T}_{16} \mathrm{E}$ ( $\mathrm{T}_{16} \mathrm{E}_{\mathrm{N}-\mathrm{C} y s}$, $\left.\mathrm{T}_{16} \mathrm{E}_{\mathrm{C}-\mathrm{Cys}}\right)$, and $\mathrm{T}_{16} \mathrm{E}^{a}\left(\mathrm{~T}_{16} \mathrm{E}^{a}{ }_{\mathrm{N}-\mathrm{Cys}}, \mathrm{T}_{16} \mathrm{E}^{a}{ }_{\mathrm{C}-\mathrm{Cys}}\right)$.

Disulfide-linked heterodimers between $\mathrm{T}_{9} \mathrm{~K}_{\mathrm{N} \text {-Cys }}$ and each of the other four derivatives were prepared by air oxidation. Undetermined amounts of the appropriate peptides were mixed in PBS buffer $(10 \mathrm{mM}$ sodium phosphate, $150 \mathrm{mM} \mathrm{NaCl}, \mathrm{pH}=9.4)$ in a $1.5 \mathrm{~mL}$ Eppendorf tube. Small holes were punched in the top of the tube to allow free air exchange. After 12 to 15 hours of exposure, the heterodimers were purified by reverse-phase HPLC: C-18 column, linear gradients of solvents A and B (defined above).

For each exchange experiment, a $2.0 \mathrm{~mL}$ solution containing $\mathrm{T}_{23} \mathrm{E} / \mathrm{K}$ and an appropriate heterodimer $(10 \mu \mathrm{M}$ total peptide concentration, $\mathrm{PBS}$ as above, $\mathrm{pH}=9.4)$ was sparged with argon for fifteen minutes in a $15 \mathrm{~mL}$ Falcon tube equipped with a small rubber septum and outlet needle. A specified amount of thiol containing peptide stock solution was quickly added to the original solution (13.3 $\mu \mathrm{M}$ final peptide concentration). A $0.5 \mathrm{ml}$ aliquot was immediately taken for HPLC analysis (conditions as above). The tube was resealed and sparged with argon for 15 minutes. The argon needle was then brought well above the solvent level and a slow, steady stream was blown through the tube for approximately 20 minutes. This process was repeated at $7 \mathrm{~h}, 24 \mathrm{~h}$, and $48 \mathrm{~h}$ time points.

Analytical Ultracentrifugation. Sedimentation equilibrium experiments were performed using a Beckman XL-I analytical ultracentrifuge equipped with an An60-Ti rotor. Data were collected using $12 \mathrm{~mm}$ path length six-sector centerpieces at $270 \mathrm{~nm}$. Samples were dialyzed against the reference buffer at $4^{\circ} \mathrm{C}$ overnight. Data were collected at 38,000 and 48,000 r.p.m. at concentrations spanning 17-55 $\mu \mathrm{M}$. Samples were equilibrated at 38,000 r.p.m. for 16 hours, followed by collection of two scans four hours apart. The speed was then increased to 48,000 r.p.m., followed by a 16 hour equilibration, and collection of two scans four hours apart, as before. Each scan consisted of 10 replicates at $0.002 \mathrm{~cm}$ radial steps. Solvent densities and partial molar volumes were calculated in the manner prescribed by Laue. ${ }^{4}$ Data were analyzed using Origin and fit to ideal single-species models.

(4) Laue, T. M.; Shah, B. D.; Ridgeway, T. M.; Pelletier, S. L. in Analytical Ultracentrifugation in Biochemistry and Polymer Science; Harding, S. E., Rowe, A. J., Horton, J. C., Eds.; The Royal Society of Chemistry: Cambridge, 1992; pp 90-125. 


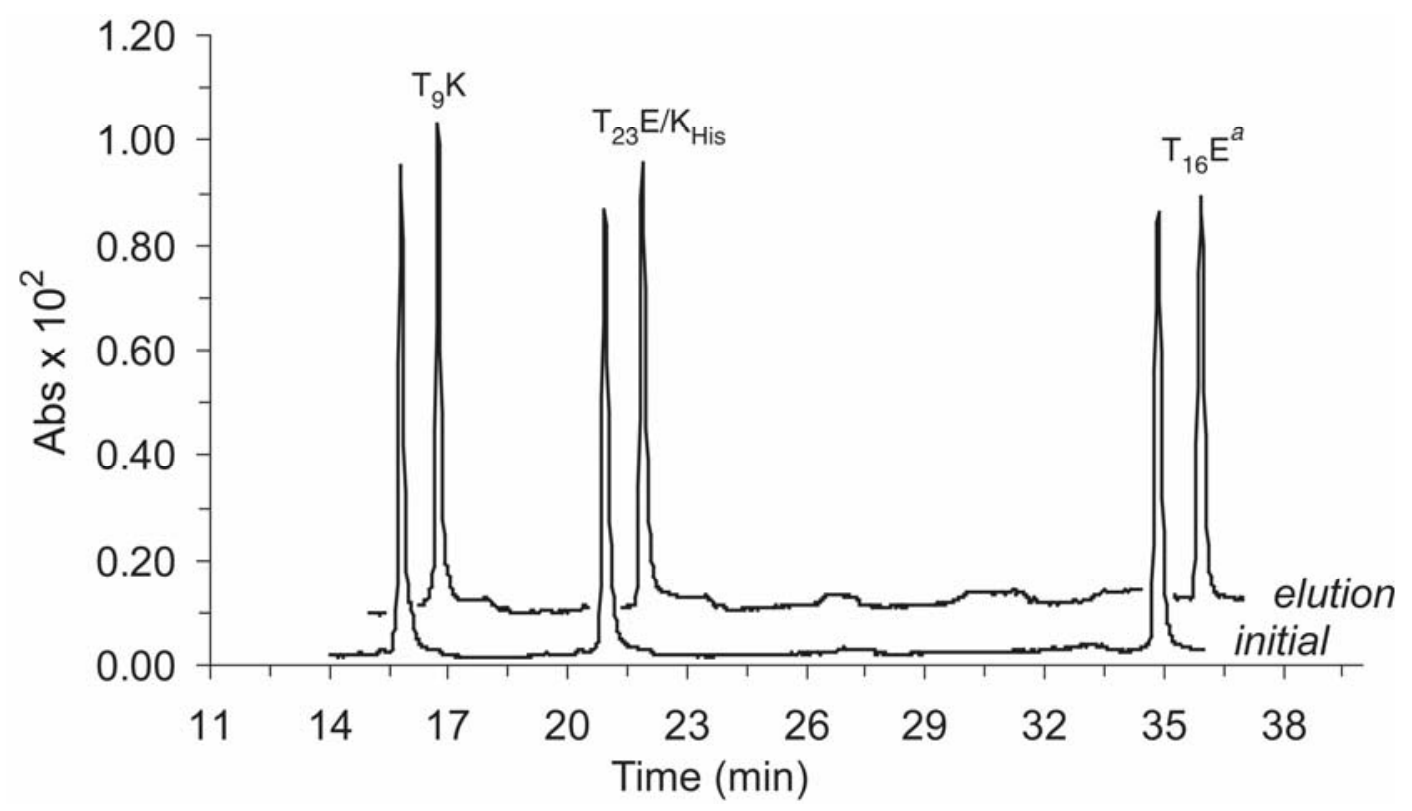

Figure S-1 Ni-NTA analysis of antiparallel complex stoichiometry. HPLC traces of initial 1:1:1 $\mathrm{T}_{9} \mathrm{~K}: \mathrm{T}_{16} \mathrm{E}^{a}: \mathrm{T}_{23} \mathrm{E} / \mathrm{K}_{\mathrm{His}}$ solution along with elution fraction demonstrating retention of one equivalent of each untagged peptide.

Initial solution compositions for Ni-NTA Affinity Tag Experiments:

Stoichiometry of Antiparallel Complex (Figure S-2):

Initial solution contained 1:1:1 $\mathrm{T}_{9} \mathrm{~K}: \mathrm{T}_{23} \mathrm{E} / \mathrm{K}_{\mathrm{His}}: \mathrm{T}_{16} \mathrm{E}^{a}$.

Hybrid Ni-NTA/Disulfide experiment on antiparallel complex (manuscript Figure 8):

Initial solution contained 1:1:1 $\mathrm{T}_{9} \mathrm{~K}_{\mathrm{N}-\mathrm{Cys}} / \mathrm{T}_{16} \mathrm{E}_{\mathrm{C}-\mathrm{Cy}}^{a}: \mathrm{T}_{9} \mathrm{~K}_{\mathrm{N}-\mathrm{Cys}} / \mathrm{T}_{16} \mathrm{E}^{a}{ }_{\mathrm{N}-\mathrm{Cys}}: \mathrm{T}_{23} \mathrm{E} / \mathrm{K}_{\mathrm{His}}$

Hybrid Ni-NTA/Disulfide experiment on register shifted complex (manuscript Figure 10):

Initial solution contained 1:1:1 $\mathrm{T}_{9} \mathrm{~K}_{\mathrm{N}-\mathrm{Cys}} / \mathrm{T}_{16} \mathrm{E}_{\mathrm{RS}-\mathrm{C}-\mathrm{Cys}}^{a}: \mathrm{T}_{9} \mathrm{~K}_{\mathrm{N}-\mathrm{CyS}} / \mathrm{T}_{16} \mathrm{E}^{a}{ }_{\mathrm{RS}-\mathrm{N}-\mathrm{Cys}}: \mathrm{T}_{23} \mathrm{E} / \mathrm{K}_{\mathrm{His}}$

Direct Antiparallel/Parallel Competition (manuscript Figure 11):

Initial solution was a 1:1:1:1 mixture of $\mathrm{T}_{9} \mathrm{~K}, \mathrm{~T}_{16} \mathrm{E}, \mathrm{T}_{16} \mathrm{E}^{a}$, and $\mathrm{T}_{23} \mathrm{E} / \mathrm{K}_{\mathrm{His}}$ in PBS buffer (13.3 $\mu \mathrm{M}$ total peptide conc., $10 \mathrm{mM}$ sodium phosphate, $150 \mathrm{mM} \mathrm{NaCl}, \mathrm{pH}=7.1$ ). Affinity experiments performed after 3, 24, 48 and $72 \mathrm{~h}$. Ratios of $\mathrm{T}_{16} \mathrm{E}$ to $\mathrm{T}_{16} \mathrm{E}^{a}$ were as follows:

Table S-1. Elution fraction ratios of $\mathrm{T}_{16} \mathrm{E}$ to $\mathrm{T}_{16} \mathrm{E}^{a}$ (from Figure 11)

\begin{tabular}{cc}
\hline Elapsed time & Parallel:Antiparallel \\
\hline initial & $51: 49^{*}$ \\
3 hours & $37: 63$ \\
24 hours & $49: 51$ \\
48 hours & $53: 47$ \\
72 hours & $55: 45$ \\
\hline
\end{tabular}

*Initial ratio of directly measured solution (not an elution fraction from an affinity experiment) 


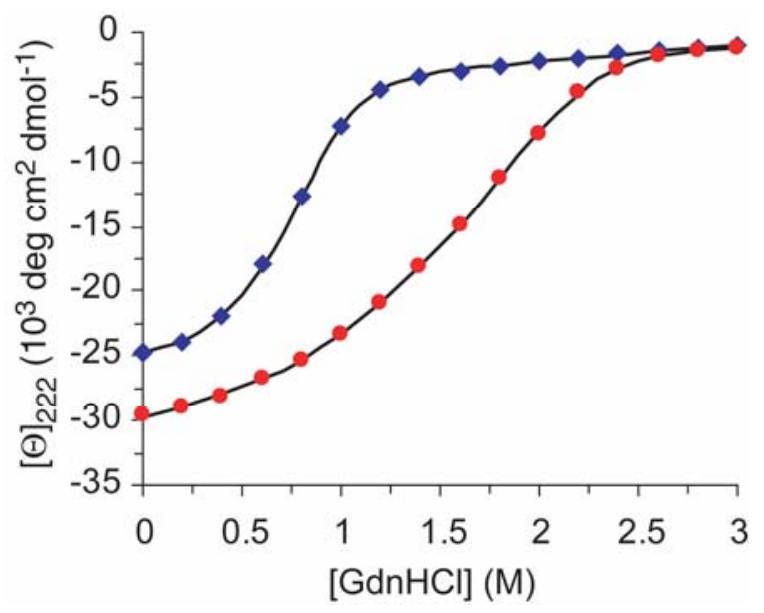

Figure S-2 GdnHCl titrations of 1:1:1 $\mathrm{T}_{9} \mathrm{~K}: \mathrm{T}_{16} \mathrm{E}^{a}: \mathrm{T}_{23} \mathrm{E} / \mathrm{K}$ (antiparallel complex, blue) and 1:1:1 $\mathrm{T}_{9} \mathrm{~K}: \mathrm{T}_{16} \mathrm{E}: \mathrm{T}_{23} \mathrm{E} / \mathrm{K}$ (parallel complex, red). Lines are fits to monomer-trimer equilibrium as described previously. ${ }^{5} \Delta \mathrm{G}_{\mathrm{unf}}=17.1 \pm 0.2$ and $18.2 \pm 0.3 \mathrm{kcal} / \mathrm{mol}$ for antiparallel and parallel complex, respectively.
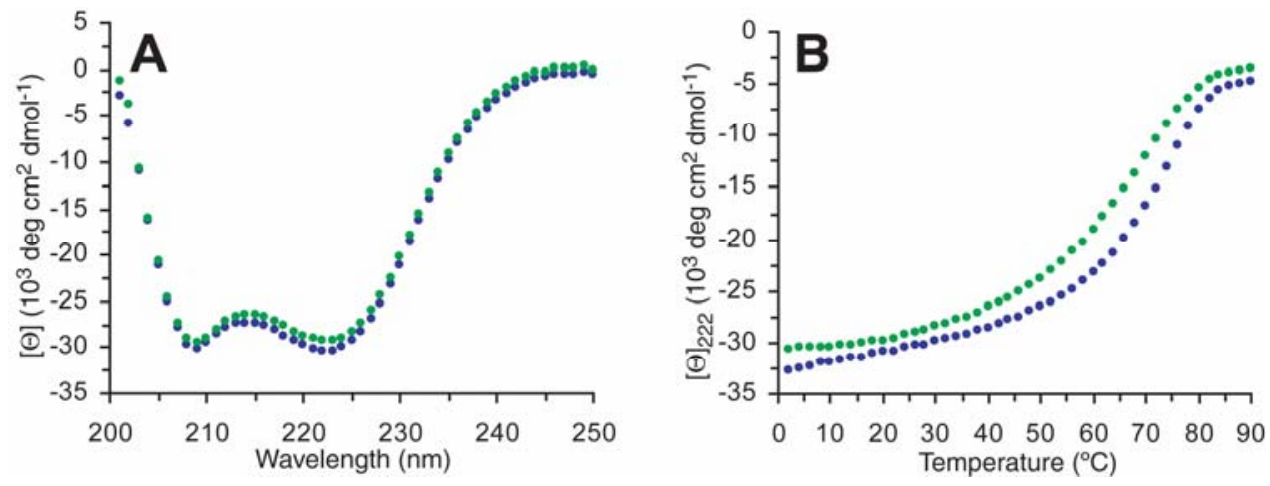

Figure S-3 Wavelength scan (A) and thermal denaturation (B) CD data for equimolar solutions of: $\mathrm{T}_{9} \mathrm{~K}: \mathrm{T}_{16} \mathrm{E}^{a}: \mathrm{T}_{23} \mathrm{E} / \mathrm{K}$ (designed antiparallel complex, blue) and $\mathrm{T}_{9} \mathrm{~K}: \mathrm{T}_{16} \mathrm{E}^{a}{ }_{\mathrm{Rs}}: \mathrm{T}_{23} \mathrm{E} / \mathrm{K}$ (control antiparallel complex, green). All samples are $10 \mu \mathrm{M}$ total peptide in PBS buffer (10 mM phosphate $\mathrm{pH}$ 7.4, $150 \mathrm{mM} \mathrm{NaCl}$ ).

${ }^{5}$ Schnarr, N. A.; Kennan, A. J. J. Am. Chem. Soc., 2002, 124, 9779-9783. 

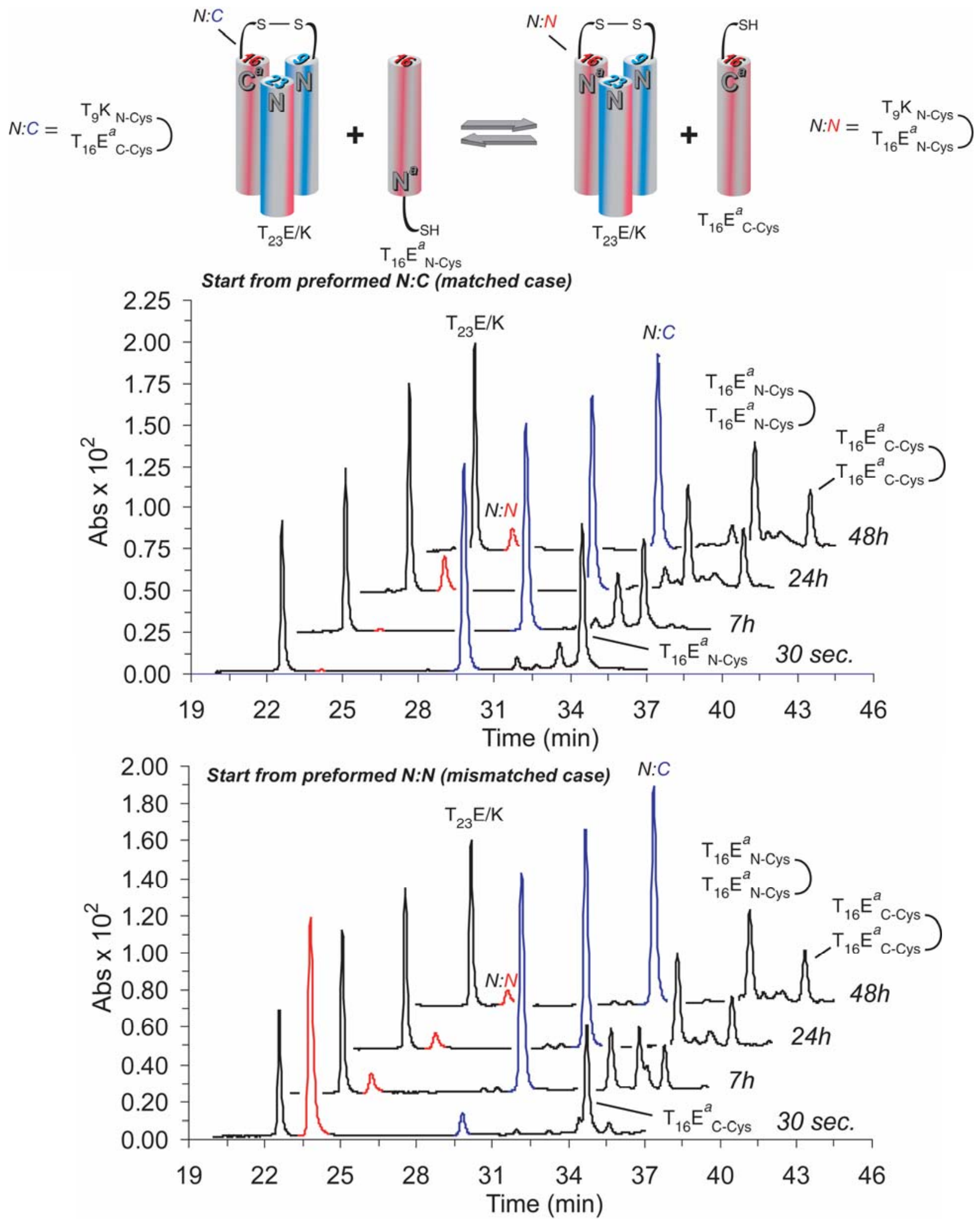

Figure S-4 Full disulfide exchange assay data for antiparallel $\left(\mathrm{T}_{9} \mathrm{~K}: \mathrm{T}_{16} \mathrm{E}^{a}: \mathrm{T}_{23} \mathrm{E} / \mathrm{K}\right)$ complex. A schematic representation of the exchange process is given, along with data from separate experiments beginning with matched or mismatched preformed disulfides (matched implies disulfide can be maintained in the favored antiparallel complex). 

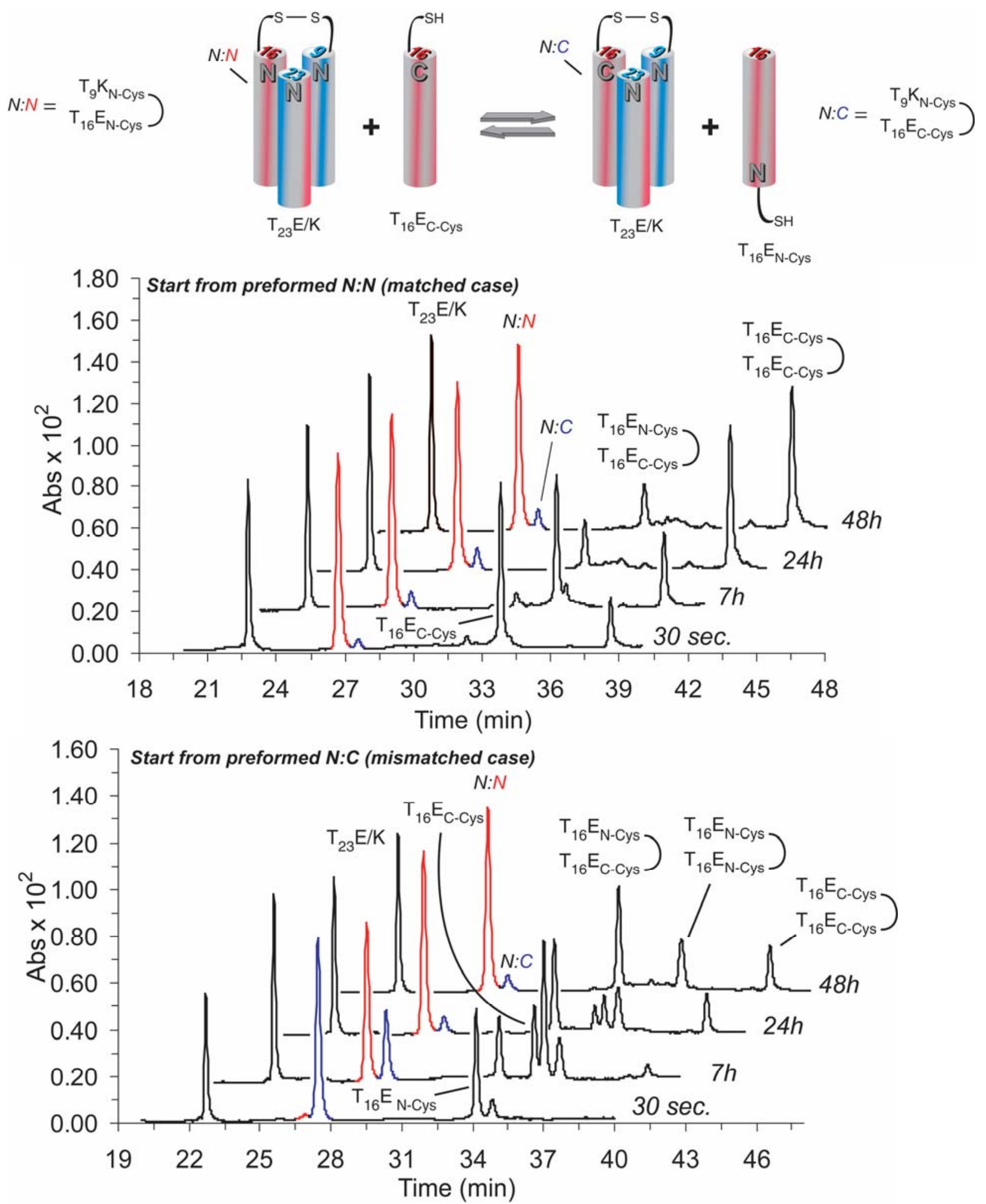

Figure S-5 Disulfide exchange assay applied to parallel ( $\left.\mathrm{T}_{9} \mathrm{~K}: \mathrm{T}_{16} \mathrm{E}: \mathrm{T}_{23} \mathrm{E} / \mathrm{K}\right)$ complex. A schematic representation of the exchange process is given, along with data from separate experiments beginning with matched or mismatched preformed disulfides (matched implies disulfide can be maintained in the favored parallel complex). 


\section{Analytical Ultracentrifugation Details}

Table S-2. Relative Molecular Masses from Analytical Ultracentrifugation ${ }^{a}$

\begin{tabular}{|c|c|c|c|}
\hline Sample & & $\mathrm{MW}_{\text {obs }} 38 \mathrm{krpm}$ & $\mathrm{MW}_{\mathrm{obs}} 48 \mathrm{krpm}$ \\
\hline \multicolumn{4}{|l|}{$T_{9} K: T_{16} E^{a}: T_{23} E / K$} \\
\hline & $17 \mu \mathrm{M}$ & 11018 & 11537 \\
\hline & $33 \mu \mathrm{M}$ & 12503 & 11924 \\
\hline & $55 \mu \mathrm{M}$ & 12671 & 11945 \\
\hline & average & \multicolumn{2}{|c|}{11933} \\
\hline & calc. (trimer) & \multicolumn{2}{|c|}{11563} \\
\hline
\end{tabular}

${ }^{a}$ All samples were in aqueous buffer (10 mM phosphate buffer, $\left.150 \mathrm{mM} \mathrm{NaCl}, \mathrm{pH}=7.0\right)$.
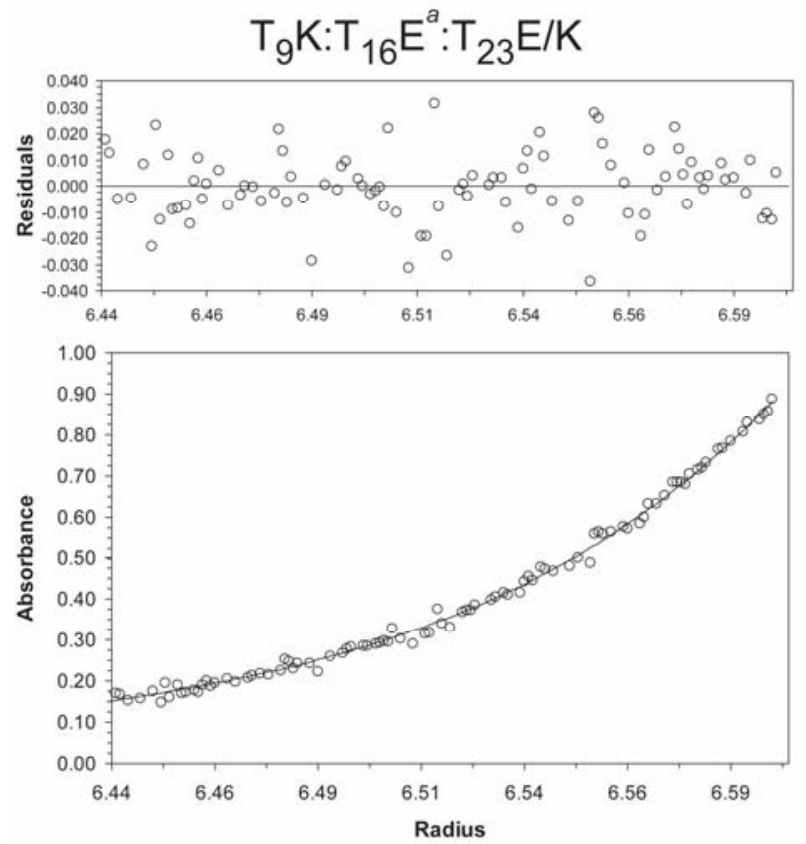

Figure S-6. Representative fit from ultracentrifugation. Data from $33 \mu \mathrm{M} 38 \mathrm{~K}$ run 